\title{
A pedagogia do herói sob as performances das políticas públicas contemporâneas
}

\author{
The pedagogy of the hero under the performances of contemporary public \\ policies
}

\section{La pedagogía del héroe bajo las performances de las políticas públicas contemporáneas}

\begin{abstract}
Eli Terezinha Henn Fabris ${ }^{1}$
Universidade do Vale do Rio dos Sinos, Professora no Curso de Pedagogia e no Programa de Pós-Graduação em Educação
\end{abstract}

Resumo: O artigo propõe uma atualização da pedagogia do herói, que é acionada nas escolas e nas instituições de ensino voltadas à formação de professores por meio de políticas públicas e movimentada pela racionalidade neoliberal no contexto global/ local. O exercício analítico utiliza-se de dados de uma pesquisa de doutoramento desenvolvida com filmes hollywoodianos e de um conjunto de pesquisas desenvolvidas sobre formação de professores com aportes teóricos das políticas educacionais e do referencial sobre docência e formação de professores em uma perspectiva hipercrítica. O estudo evidencia que a pedagogia do herói produz regras para o processo de avaliação e estimula performances cada vez mais altas dos professores e das instituições de formação docente no cenário brasileiro. Nessa pedagogia, o professor é colocado na posição de herói, e a docência, mediante uma lógica concorrencial, torna-se uma atividade qualificada, atingida por meio de premiações e bons resultados de avaliações em larga escala. Como desdobramentos deste estudo, apresentam-se alguns desafios para que se possam subverter os efeitos da tal pedagogia. Os resultados apontam para a necessidade de uma constante suspeita da visão de pedagogia do herói e das políticas públicas contemporâneas neoliberais, que precisam passar sob o escrutínio permanente da crítica radical.

Palavras-chave: Pedagogia do Herói. Políticas públicas. Docência. Performatividade.

Doutora e Mestre em Educação pela Universidade Federal do Rio Grande do Sul. 
Abstract: This paper proposes the updating of the pedagogy of the hero, which is both triggered in schools and educational institutions intended for teacher education by means of public policies, and driven by the neoliberal rationality in the global/ local context. The analysis has used data from a doctoral research on Hollywood movies and as well as a group of researches on teacher education using theoretical contributions of educational policies and references about teaching and teacher education from a hypercritical perspective. The study has evidenced that the pedagogy of the hero produces rules for the evaluation process and requires increasingly higher performances from both the teachers and the teacher education institutions in the Brazilian scenario. In this pedagogy, teachers are positioned as heroes, and teaching, through a competitive logic, becomes a qualified activity, which is achieved by means of rewards and good results in large-scale evaluations. As a derivation of this study, some challenges have been presented in an attempt to subvert the effects of that pedagogy. The results have pointed out the need for a constant suspicion of the view of the pedagogy of the hero and contemporary neoliberal public policies, which should be permanently scrutinized by radical criticism.

Keywords: Pedagogy of the hero. Public policies. Teachers. Performativity.

Resumen: El artículo propone una actualización de la pedagogía del héroe, que es accionada en las escuelas e instituciones de enseño, volcadas a la formación de profesores por medio de políticas públicas y movida por la racionalidad neoliberal, en el contexto global/local. El ejercicio analítico se vale de datos de una investigación de doctorado desarrollada con películas hollywoodenses y de un conjunto de investigaciones desarrolladas sobre formación de profesores con aportes teóricos de las políticas educacionales y del referencial sobre la docencia y formación de profesores en una perspectiva hipercrítica. El estudio evidencia que esa pedagogía produce reglas para el proceso de evaluación y estimula performances cada vez más altas para el desempeño docente y para las instituciones de formación docente en el escenario brasilero. En esta pedagogía, el profesor es colocado en la posición del héroe y la docencia se torna una actividad calificada mediante una lógica competitiva, alcanzada por medio de premiaciones y resultados de evaluaciones a gran escala. Como desdoblamientos de este estudio, se presentan algunos desafios para que puedan profundizar los efectos de tal pedagogía. Los resultados apuntan a la necesidad de una constante sospecha sobre la visión de pedagogía del héroe y de las políticas públicas contemporáneas neoliberales, que necesitan pasar por el escrutinio permanente de la crítica radical.

Palabras clave: Pedagogía del héroe. Políticas públicas. Docencia. Performatividad. 


\section{SITUANDO A QUESTÃo}

\begin{abstract}
Os filmes hollywoodianos usam diferentes pedagogias para construir o seu modelo de escola, que é centrado na figura do herói, do salvador e sacerdote. Esses personagens carismáticos e com uma grande força de persuasão e envolvimento com o grupo de alunos e alunas são impulsionados a resolver problemas e vencer desafios. Mostram com seus exemplos, com sua forma de agir, que não há barreiras quando se quer alguma coisa, quando se decide lutar por ela, estimulando a competição e o individualismo. (FABRIS, 1999, p. 137-138).
\end{abstract}

A pedagogia do herói não circula apenas em filmes, como expressa a epígrafe escolhida para iniciar este texto. Faz-se cada vez mais intensa, no momento atual na sociedade brasileira, essa forma de exercer a docência e de constituir-se professor ou professora a partir de diferentes, variadas e altas performances. Em uma pesquisa publicada anteriormente por Fabris (1999), em que foram analisados filmes hollywoodianos, identificou-se que a pedagogia do herói era a mais recorrente nessas películas. Hoje vejo que essa pedagogia extrapola os filmes e que foi identificada e descrita também em outras pesquisas, como a de Oechsler e Silva (2012), que analisaram a Revista Nova Escola, a de Vicentini e Alves (2012), na revista Veja, ou o estudo de Fischman (2009), que considera os limites e as possibilidades das narrativas redentoras em educação. Esses estudos são unânimes em mostrar o professor descrito como um herói. É notório que práticas docentes com essas marcas de heroísmo e salvacionismo estão circulando na constituição do ser professor ou professora no Brasil, bem como em outros países/regiões, e estão presentes nos diferentes artefatos da cultura contemporânea.

No entanto, o que se pretende mostrar neste estudo é como essa pedagogia do herói se atualiza no contemporâneo, na medida em que está mergulhada em uma atmosfera neoliberal, ou seja, a racionalidade neoliberal movimenta essa pedagogia e a constituição do professor herói. Com tal objetivo, a seguir, propõe-se três movimentos argumentativos. No primeiro movimento, apresento como a narrativa heroica é construída, mostrando a celebração dos heróis durante o desenvolvimento da civilização. No segundo movimento, mostro como a concepção de pedagogia do herói circula em artefatos da cultura e na escola da Modernidade. No terceiro movimento, 
apresento as políticas públicas e os organismos internacionais que constituem as práticas educativas contemporâneas.

No bojo deste último movimento, mostro como algumas pesquisas, desenvolvidas tanto pelo grupo de pesquisa GIPEDI ${ }^{2}$ quanto por outros pesquisadores, identificam a racionalidade neoliberal, produzindo a pedagogia e o professor, que são posicionados em um alto nível de excelência e, por isso, elevados à condição de modelos. Nesse processo, a cultura da performatividade atua na constituição dos sujeitos, produzindo altas performances, que devem ser atingidas por todos. O que vemos emergir é um professor herói que desenvolve uma pedagogia para este tempo.

Dando continuidade aos argumentos, apresento algumas questões suscitadas pelas pesquisas analisadas e busco pensar outras formas de exercer a docência e de ser professor no contemporâneo. Para finalizar, aponto alguns desafios que podem ajudarnos a pensar e agir na contramão das atuais políticas públicas e artefatos da cultura que trazem na sua gênese um compromisso com a escola-empresa e compreendem o próprio sujeito contemporâneo como um empresário de si.

\section{EDUCAÇÃO E POLÍTICAS PÚBLICAS NEOLIBERAIS: ATUALIZAÇÃO DA PEDAGOGIA DO HERÓI}

A narrativa heroica circula em nossa sociedade e no imaginário social desde tempos imemoráveis. Nos primeiros registros históricos do mundo ocidental, a Ilíada e a Odisseia narram as aventuras de um herói grego, Ulisses. Homero é considerado o primeiro historiador. Os heróis habitam nosso imaginário, quer pela força dos mitos, nos heróis mitológicos, quer pelos super-heróis que nos servem de modelos de força, bondade, solidariedade, bravura, beleza, inteligência e outros atributos cada vez mais avançados, conforme o tempo em que esses heróis tiveram sua emergência. Eles também aparecem em variadas histórias que fazem parte do registro histórico de nossa civilização ou em complexas histórias de ficção.

Ficção ou realidade, não importa. O que essas histórias tão peculiares produzem são narrativas que envolvem vários personagens em uma jornada ${ }^{3}$ ou

\footnotetext{
2 Trata-se do Grupo Interinstitucional de Pesquisa em Pedagogias, Docências e Diferenças (Gipedi/ $\mathrm{CNPq}$ ), com sede na Universidade do Vale do Rio dos Sinos (Unisinos).

3 Evento de um dia.
} 
em uma odisseia ${ }^{4}$ própria de cada herói. Campbell (1995), na obra chamada de $O$ Herói de mil faces, aborda a narrativa heroica com aspectos que muitos diretores e produtores de cinema desenvolvem em seus filmes, caracterizando as histórias heroicas de nossos tempos. As mesmas etapas são retomadas, mas recolocam-se as narrativas em nosso tempo. Sinteticamente, esses heróis vivem uma rotina (vida comum); depois, há uma mudança na vida do herói, há um momento de recusa ao chamado, em que o herói passa por dúvidas, até tomar a decisão de enfrentar o desafio. Posteriormente, há o encontro com o mentor, momento em que o herói é aconselhado e orientado por alguém; em seguida, ocorre a travessia, quando ele caminha para tornar-se herói. Para isso, ele precisa passar por testes, podendo contar com aliados na luta contra os inimigos. Há um tempo de treinamento, em que ele se prepara para enfrentar o inimigo, indo ao extremo das suas capacidades, para deixar o seu lado humano e firmar-se plenamente como herói. No momento do desafio, ele enfrenta o perigo, prova que é definitivamente herói e recebe uma recompensa. Geralmente, há um caminho de volta, que envolve perseguição e aventuras. Na etapa da ressurreição, o herói volta, trazendo o elixir, a solução, a transformação e/ou salvação para todos (SANTOS; FERREIRA, 2015).

São exemplares desses feitos as histórias mitológicas dos heróis gregos, entre eles: Aquiles, excelente guerreiro; Hércules, cuja força física era a principal qualidade; Teseu, que derrotou o Minotauro em Creta; Agamenon, que foi guerreiro na guerra de Tróia. Bem mais contemporâneas são as histórias que habitam o imaginário infantil por meio de super-heróis, como Batman, Super-Homem, Mulher Maravilha e outros que a cada dia invadem nossa vida cotidiana. Há, ainda, filmes como Indiana Jones, Harry Potter, StarWars e outros que ocupam as telas de cinema e/ou as de televisão de nossas casas. São histórias com a mesma sequência na narrativa, que, em síntese, podemos usar para caracterizar um herói. Os heróis servem aos necessitados com um amor altruísta, não são movidos por interesses pessoais. São seres que se distinguem dos demais - sua dimensão divina e suas capacidades fora do que é considerado normal ficam evidentes em cada história. O vilão a enfrentar define o tamanho e o valor do herói. Em geral, os heróis juvenis definem-se com uma capacidade física e coragem além do normal, enquanto os mais adultos distinguem-se

\footnotetext{
4 Viagem que conta com uma série de aventuras e acontecimentos extraordinários em um período temporal mais longo.
} 
pela sedução, persuasão, inteligência - são outras as qualidades que os fazem heróis. Eles enfrentam missões, provas, e não problemas, mas sempre vencem ao final e levam o bem para toda uma comunidade, cidade, vila, humanidade, escola e/ou sala de aula.

Essa celebração dos heróis na sociedade contemporânea é envolta por uma cultura de performatividade em que as altas performances são colocadas como parâmetros de avaliação e desempenho. Ball (2005, p. 543, grifo do autor), na passagem abaixo, ajuda-nos a entender esse conceito:

A performatividade é uma tecnologia, uma cultura e um método de regulamentação que emprega julgamentos, comparações e demonstrações como meios de controle, atrito e mudança. Os desempenhos de sujeitos individuais ou de organizações servem de parâmetros de produtividade ou de resultado, ou servem ainda como demonstrações de "qualidade" ou "momentos" de promoção ou inspeção.

É nessa cultura que se desenvolve a pedagogia do herói, atualizada nestes tempos de altas performances, produzindo um jeito de ser professor e de docência que se coadunam com tal cultura. Nesse cenário, é importante considerar o que acontece em países como o Brasil em termos de orientação e regulação pelas políticas públicas. Mobilizadas por organismos internacionais e pelos impactos da globalização, tais políticas têm efeitos, podendo atuar por inclusão ou por exclusão.

Os organismos internacionais, como o Banco Mundial (BM), a Organização para a Cooperação Econômica e Desenvolvimento (OCDE), a Comissão Econômica para a América Latina e o Caribe (Cepal) e o Fundo Monetário Internacional (FMI), entre outros, emergem na esteira das necessidades do pós-guerra. Programas de assistência econômica e de empréstimos voltados às políticas de industrialização e de reconstrução dos países deram a tônica de ação para esses organismos. O entendimento era que, com o crescimento econômico das nações, a pobreza desapareceria (AÇÃO EDUCATIVA, 2005; KORITIAKE, 2010). Os países em desenvolvimento tiveram, na década de 1980, uma função importante de reorientação das políticas públicas, principalmente na América Latina, onde, pelo endividamento dos países, estes ficaram à mercê de cláusulas impostas pelos organismos internacionais na renegociação das dívidas externas. No Brasil, essas políticas ganham maior potência na década de 1990, em que imperam as políticas neoliberais e quando o Estado assume outra reconfiguração, passando a funcionar como um Estado empresa. Nas palavras do professor Veiga-Neto (2000, p. 198, grifo do autor), esse argumento torna-se mais claro: 
O que está ocorrendo é uma reinscrição de técnicas e formas de saberes, competências, expertises, que são manejáveis por "expertos" e que são úteis tanto para a expansão das formas mais avançadas do capitalismo, quanto para o governo do Estado. Tal reinscrição consiste no deslocamento e na sutilização de técnicas de governo que visam fazer com que o Estado siga a lógica da empresa, pois transformar o Estado numa grande empresa é muito mais econômico - rápido, fácil, produtivo, lucrativo. Isso sem falar que as próprias empresas - principalmente as grandes corporações - têm muito a ganhar com o empresariamento do Estado.

Com as políticas neoliberais, que colocam em pauta a concorrência, o Estado toma outra configuração ao funcionar como um Estado empresa. Assumindo uma função muito mais avaliadora, aparenta ser um Estado mais enfraquecido, mas potencializa-se na ação de parceria com toda a população. Nesse processo, o conceito de governamentalidade, criado por Michel Foucault e entendido como práticas de governo que têm "na população seu objeto, na economia seu saber mais importante e nos dispositivos de segurança seus mecanismos básicos” (MACHADO, 1979, p. XXIII), ganha especial relevância. Ele é útil para entendermos que, em uma governamentalidade neoliberal, essa lógica passa a orientar a vida e a constituir as próprias pessoas. Nesse sentido, é elucidativo o que o filósofo aponta na obra Nascimento da Biopolítica, em que argumenta que, em uma sociedade regulada pelo mercado, o princípio regulador não é tanto a troca de mercadorias, mas os mecanismos da concorrência - mais do que uma sociedade de supermercado, é uma sociedade empresarial (FOUCAULT, 2008).

\section{A PEDAGOGIA dO HERÓI NAS PESQUISAS CONTEMPORÂNEAS}

Ao analisar um conjunto de filmes de escola, ${ }^{5}$ de procedência hollywoodiana, percebe-se a mesma trama narrativa. Na pesquisa, ficou evidente essa forma de ser e agir na docência a qual passei a denominar de pedagogia do herói. " [...] os modelos apresentados nos filmes são inatingíveis para os mortais professores e professoras de

\footnotetext{
5 Os filmes analisados foram: Sociedade dos Poetas Mortos, Ao mestre com carinho I e II, Mr. Holland, adorável professor, Conrack, O substituto I e II, Meu mestre, minha vida, A história de Marva Collins, Escola da desordem, Momentos decisivos, Curso de férias, Um tira no jardim de infância, Mentes que brilham, Sarafina, o som da liberdade e Mentes perigosas.
} 
nossas escolas. É sobre esse modelo de pedagogia que os filmes hollywoodianos por mim analisados pautam suas histórias.” (FABRIS, 2010, p. 235).

Nos filmes analisados, os professores - em sua maioria homens desenvolviam ações heroicas que faziam deles superprofessores que precisavam cotidianamente viver a superação e desenvolver formas altruístas de viver, doandose integralmente para a vocação. Nesses filmes, as relações espaço-temporais predominantes foram as da Modernidade, o que mostrava uma forma de ensinar e de aprender com ênfase nas pedagogias disciplinares, com poucos deslocamentos para outras relações. A pedagogia do herói era a forma de ser professor e desenvolver a docência que mais intensamente circulava nesses filmes. Fischmann (2009) esclarece que essa representação de professor herói que circula nas pedagogias que o autor chama de progressistas colocam uma distância e uma impossibilidade de que todos os professores se sintam comprometidos com uma ação transformadora; por isso, ele vai propor um deslocamento do "professor herói para um intelectual comprometido".

É importante referir que outras pesquisas também constataram essa pedagogia em ação e a mesma identificação com o professor herói, indicando certa atualização dessa pedagogia na Contemporaneidade, atravessada por outras relações de poder e outros sistemas de verdades que a sustentam.

A partir daqui, citam-se algumas pesquisas que mostram como as pedagogias engendradas pelas políticas públicas estão em sintonia com a pedagogia do herói. Neves (2016) discute na sua dissertação de mestrado a qualidade na formação de professores, analisando o selo 5 Estrelas para as licenciaturas no Brasil, emitido pelo Guia do Estudante, da Editora Abril. A autora mostra como a racionalidade neoliberal vai mobilizando a competição e o ranqueamento dos cursos e, com isso, destinando a cada um uma posição estratégica, em que o imperativo da qualidade mobiliza a tudo e a todos para que atinjam as metas e hierarquias preestabelecidas.

Outra pesquisa que toma um prêmio para analisar é a de Ferreira (2015). Ele analisa o Prêmio Professores do Brasil e mostra como este funciona como uma economia da educação. Ele demonstra que o Prêmio Professores do Brasil, promovido pelo Ministério da Educação e seus parceiros, atua por meio da "espetacularização da carreira docente". Nessa análise, fica visível o quanto a "subjetividade docente superlativa", como o pesquisador denomina essa subjetividade produzida pelo prêmio, é um jeito de ser e agir que se traduz e se apresenta tal qual o que denomino como pedagogia do herói. 
A espetacularização da carreira docente contribui para que os projetos e/ ou práticas pedagógicas sejam lançados e exaltados como modelos de "boas práticas" e para que a "subjetividade superlativa" seja tomada como a subjetividade do que se constitui como "o bom ou a boa professora". Viver a docência sob os mandatos dos prêmios é entrar no jogo concorrencial e aceitar que, se alguns podem ser excelentes professores, mesmo em condições inóspitas, todos poderão sê-lo, não importando se as causas são apenas pedagógicas ou não. O que vale é esforçar-se para colocar em ação essa subjetividade superlativa; com a espetacularização, tanto dessa subjetividade quanto das boas práticas, tudo será resolvido - eis a economia da educação produzindo-se.

É válido inserir nesse conjunto de pesquisas a dissertação de mestrado de Scherer (2015), intitulada Cada um aprende de um jeito: das adaptações às flexibilizações curriculares. Nesse estudo, a pesquisadora mostra-nos uma docência flexível colocada em cena por um professor que passa a ser igualmente exigido como flexível para que possa flexibilizar também os currículos escolares. A pesquisadora analisa dois conjuntos de materiais - documentos legais e revistas pedagógicas e mostra o quanto passamos de uma ênfase disciplinar para outra ênfase, agora de controle, e como isso produz alterações nas práticas e nos sujeitos que passam a agir sob o imperativo da flexibilidade. Tudo isso para que seja mais econômico ensinar e aprender, pois, dentro da lógica do Estado empresa, todos precisam fazer parte do jogo concorrencial.

Ao dar andamento a esse recorrido por algumas pesquisas, cito, ainda, duas teses: a de Oliveira (2015) e a de Brodbeck (2015). As duas pesquisas investigam materiais do Programa Interinstitucional de Bolsa de Iniciação à Docência (PIBID), uma no Curso de Pedagogia e outra no Curso de Biologia. A pesquisadora que analisa o Curso de Pedagogia defronta-se com uma docência que ela chamou de virtuosa, a qual se desenvolve por três formas de ação - comprometida, tática e interventora e por meio de uma subjetividade pibidiana (OLIVEIRA, 2015). A autora identifica uma docência e um professor adequados à mesma lógica empresarial e de um Estado governamentalizado. Já Brodbeck (2015) depara-se com uma pedagogia da redenção, produzida na interface das pedagogias críticas e psicológicas, em que "superbolsistas" são produzidos como modelos de bons professores.

$\mathrm{O}$ que pretendi mostrar com essa digressão, que rememorou algumas pesquisas, é que a "subjetividade superlativa", cunhada por Ferreira (2015), parece 
constituir cada professor e professora no contemporâneo, senão na sua vida, ao menos no seu desejo e frustração de não pertencer ainda ao seleto grupo daqueles que habitam e desenvolvem a pedagogia do herói e que, por isso, passam a viver sob a “espetacularização de docência”, produzindo novas demandas para a formação. Não basta ser um bom professor ou uma boa professora - é preciso viver a espetacularização, ser premiado, ser, viver e apresentar-se como um professor herói.

Destaca-se, ainda, que as políticas com forte ênfase neoliberal já chegaram e habitam nossas escolas, não estando mais apenas em países distantes e mais desenvolvidos. Estamos vivendo em nossas escolas e em nossas universidades outras relações espaço-temporais: aceleração, tempo digital, tempo pontilhista, que impactam em novas subjetividades de alunos e professores. Diante desse panorama, é preciso muita atenção, pois, junto com o brilho e sedução da inovação, podemos estar renovando antigas práticas e pedagogias que serviram muito bem em um tempo analógico, mas que hoje podem funcionar para que a exclusão se fortaleça ainda mais entre grupos sociais distintos, que não possuem no social o mesmo capital cultural, assim agudizando as diferenças entre ricos e pobres, entre aprendentes e não aprendentes, entre escolarizados e não escolarizados.

\section{OS DESAFIOS DAS PEDAGOGIAS CONTEMPORÂNEAS}

Ao argumentar sobre a atualização da pedagogia do herói, é possível evidenciar a racionalidade neoliberal produzindo a performance dessa pedagogia, em que o professor é colocado na posição de herói, e a docência se torna uma atividade qualificada mediante uma lógica concorrencial, atingida por meio de prêmios e modelos performáticos. Para chegar a essa performance, usam-se as avaliações em larga escala, em diferentes níveis e gradientes, utilizando-se critérios cada vez mais exigentes para atingir altos desempenhos e usando-se a mídia para visibilizar as práticas e as instituições que aceitam a interpelação dessa lógica e o desafio da pedagogia do herói, sendo acionadas e visibilizadas como modelos a serem alcançados.

Diante desse jogo, é importante considerar os desafios que enfrentamos cada vez mais para vivermos em uma sociedade mais justa e menos excludente. As causas são colocadas para que os heróis, aqueles que aceitam viver sob os imperativos da pedagogia do herói, passem a defendê-las e a dar a própria vida por elas, mas sempre de forma solitária e meritocrática, nunca sem sofrimento, culpa e frustração. 
Ball (2005, p. 551, grifo do autor) alerta que, “[...] além da fria racionalidade da performatividade vinculada à culpa e ao tormento de querer ser 'um bom professor', existe a revolta da moral pública, construída em nosso nome na mídia, que se destina a difamar a 'pior escola' e 'professores que deixam a desejar'."

Em outro texto, Veiga-Neto (2005) chama atenção para uma característica da pedagogia moderna que ele denomina de "sete pragas". Entre elas estariam: "transcendentalismo, o finalismo, o catastrofismo (com seu correlato denuncismo), o salvacionismo, o prometeísmo, o prescritivismo (com seus correlatos metodologismo e reducionismo) e o messianismo (com seu correlato fundamentalismo)." (VEIGANETO, 2005, p. 9). Se a pedagogia moderna alimenta-se desses preceitos, na Contemporaneidade, e sob a cultura da performatividade, podemos perceber um acirramento ainda maior desse quadro, mobilizado na pedagogia do herói. Então, é preciso que pensemos no que essas pedagogias nos colocam como desafios.

Com esse objetivo, é necessário reforçar mais três pontos: a função da escola, o lugar do conhecimento e as pedagogias que circulam nas escolas de nosso tempo. Diante da reconfiguração do Estado, novas funções passam a ser assumidas pela escola. Nóvoa tem uma definição muito produtiva para esse fenômeno, que ele vai denominar de escola transbordante, quando aborda a educação escolarizada:

[...] há uma espécie de valorização retórica dos professores. Pede-se de tudo a eles. Quem vai salvar o mundo? Quem vai assegurar o desenvolvimento de todos? Quem vai garantir o progresso? Para todas essas questões, a resposta é sempre a mesma, a Educação. Algumas instituições parecem caminhões enormes carregando toneladas, mas eles têm rodinhas de bicicleta no lugar de pneus grandes. A Educação assumiu muitas tarefas. É o fenômeno da escola transbordante. (NÓVOA, 2012).

Esse fenômeno não é novo, mas, no cenário da governamentalidade neoliberal, toma um acento na dimensão da parceria, e todos da comunidade educativa passam a participar de forma muito intensa na posição de parceiros a fim de levar a cabo as funções do Estado. É importante considerar que as pedagogias mais acionadas são as pedagogias ativas, que se desdobram em atividades lúdicas, prazerosas, interessantes, lançam mão das tecnologias, de atividades fora da sala de aula e procuram resolver um problema de cunho social, isto é, exercer a salvação ou ato de heroísmo. A pedagogia das proteções (SILVA; FABRIS, 2016) e a pedagogia redentora (BRODBECK, 2015) tornam-se o mantra nas escolas. O professor adequado 
a essas pedagogias é o professor mediador, aquele que está mais preocupado em organizar o meio e regular os tempos e espaços escolares. Ele precisa assumir a função de facilitador das aprendizagens, ser flexível, ser um professor tático e interventor (OLIVEIRA, 2015) que tem no fazer, na ação, um imperativo docente. Ele precisa fazer tudo, providenciar os meios para que os alunos possam "aprender a aprender" e a tornar-se protagonistas; com isso, eles passam a ter menos atuação e troca entre colegas, o coletivo é esvaziado, o individualismo é acentuado.

Diante de uma escola que protege (SILVA; FABRIS, 2016), consolida-se cada vez mais uma separação entre as escolas para “os filhos dos outros" e "para os nossos filhos". Nessa separação, quem carrega o ônus da ignorância e da fragilização dos conhecimentos é a escola para "os filhos dos outros", que tomará a ênfase na proteção como pedagogia. Os conhecimentos passam a ter acento na avaliação e nos comportamentos, sendo mais econômico passar por vários processos de avaliação daquilo que é considerado conteúdo e do próprio comportamento do aluno do que colocar o foco no ensino. Entre o ensino e a aprendizagem, a ênfase é colocada na aprendizagem, pois o foco é individualizante e, em caso de fracasso, é o sujeito que será responsabilizado.

A docência geralmente é comprada em programas de apostilamento, embalada em novas tecnologias ou até mesmo terceirizada. O que importa é a espetacularização dos programas, sua variação, sua flexibilização e a idealizada inovação. Não são valorizados os processos formativos e coletivos do grupo de professores de cada escola, visando ao ensino e às aprendizagens escolares, bem como à educação das crianças, jovens e adultos que chegam às escolas e estão centralmente vinculados à história de sua comunidade.

A formação de professores é desenvolvida de formas variadas, mas atualmente ganham centralidade as que se utilizam da rapidez, da aceleração. Em alguns países, como, por exemplo, os EUA, a formação é oferecida fora das universidades, com as "rotas alternativas" (ZEICHNER, 2013). Os apostilamentos passam a configurar-se como formas de desenvolvimento da formação continuada de professores que invadem cada vez mais as escolas e as Secretarias de Educação. Muitos desses programas não contribuem para a qualificação dos processos formativos dos professores, pois acabam homogeneizando práticas que são peculiares a cada escola e região. O trabalho de Bergold (2014, p. 6), ao analisar um desses programas, o Formar em Rede, desenvolvido entre os anos 2009 e 2011 pelo Instituto Avisa Lá (São 
Paulo) e pela Secretaria Municipal de Educação de Novo Hamburgo (RS), constatou que "[...] a supervisão escolar na Contemporaneidade, ligada à cultura empresarial, responde produtivamente a tal chamado, configurando-se como uma supervisão que adere ao formato empresa, portanto, uma 'supervisão S/A', que fabrica uma supervisora gerente."

Diante desse quadro, é possível perceber que as políticas públicas são reguladas cada vez mais pelas políticas de accountability, ${ }^{6}$ as quais atuam basicamente em três dimensões: avaliação, prestação de contas e responsabilização, buscando a parceria, mas, ao avaliarem, colocam o ônus sobre o sujeito (AFONSO, 2009). Não se trata de uma responsabilidade assumida coletivamente e compartilhada, mas de um processo de individualização que avalia com base em critérios das avaliações em larga escala, que premiam quem vence, que passa a ser considerado o modelo para todos. No entanto, a empresa/instituição não se responsabiliza por quem não consegue alcançar o modelo instituído. Se um sujeito conseguiu, todos devem conseguir, não importando as condições individuais e de contexto. Essa é uma das faces, talvez a mais perversa, da lógica concorrencial das políticas de accountability, que passam a funcionar como energia mobilizadora das práticas meritocráticas, tão exaltadas no trabalho docente contemporâneo.

\section{PARA ENFRENTAR OS DESAFIOS CONTEMPORÂNEOS}

Acredita-se na pesquisa como produção de conhecimentos científicos e como ação política capaz de mobilizar os sujeitos para assumirem atitudes e, portanto, transformarem-se. $\mathrm{Na}$ educação, uma das formas de oxigenar os espaços das escolas e das instituições educativas é por meio da pesquisa. A pesquisa pode fomentar a inquietação e a curiosidade, que são responsáveis pela inovação dos processos de ensinar e aprender, envolvendo os processos educativos. Ela pode ajudar-nos a fazer a apropriação crítica da experiência, como nos ensina Hermann:

[...] o hábito da reflexão e da pesquisa nos prepara para produzir compreensões próprias, coincidentes, em vários aspectos, com muitas teorias. Para além de clichês, jargões acadêmicos e tri-

\footnotetext{
6 Utilizado como sinônimo de prestação de contas, mas esse vocábulo tem abrangência e significação mais complexa. Usado no campo da gestão, vem imperando em todos os âmbitos da educação, prestando-se a uma lógica neoliberal por excelência. No Brasil, começa a expandir-se a partir dos anos 1990 (SCHNEIDER; NARDI, 2015).
} 
vialidades, precisamos de formação, refinamento do intelecto e da sensibilidade para fazer uma apropriação crítica da própria experiência. (HERMANN, 2014, p. 28).

A partir desse momento, para não abandonar o leitor em uma espécie de labirinto e para continuar pensando a formação de professores sobre outras bases, apresento alguns argumentos que podem ajudar a enfrentar esses desafios que se impõem no contemporâneo.

A primeira questão que apresento para pensar é o conceito de formação que assumimos nas instituições de formação de professores. $\mathrm{O}$ que entendemos por formação?

\begin{abstract}
Na atualidade, tempo de crescimento e de ampliação de políticas neoliberais, o conceito de formação tem sido cada vez mais atrelado ao processo pelo qual se pode atingir um conjunto de competências, um processo pautado por rankings, um processo que forma sujeitos capazes de empreender e de se tornar empreendedores de si mesmos. Com isso, observamos um declínio do conceito de formação como Bildung e uma ascensão do conceito de formação como um posicionamento estratégico de mercado. O que pretendemos mostrar é que esse conceito produz "formações aceleradas", que podem ser compradas em pacotes e subsidiadas em suaves prestações. (DAL'IGNA; FABRIS, 2015, p. 81).
\end{abstract}

Se o conceito de formação assumido é frágil, todo o currículo vai produzir sujeitos sob essas condições. Para contrapor-se a esse modelo de formação, assumo como uma possibilidade e um desafio o conceito de ethos de formação como "certo modo de ser e de agir, resultado de processos pelos quais cada um aprende a ver a si mesmo, a refletir sobre suas próprias ações, a operar transformações sobre si mesmo, este processo amplia-se e cria uma cultura de pertencimento, uma 'morada', uma comunidade partilhada.” (DAL'IGNA; FABRIS, 2015, p. 78, grifo do autor).

Esse processo envolve não apenas o sujeito em formação, mas o professor, a escola onde vai atuar, os colegas mais experientes e a universidade. Para que seja um conceito produtivo, o ethos de formação precisa estar em relação, em funcionamento. O sujeito deve estar em relação e exercendo o pensamento em todas as fases do processo de sua constituição e formação para se tornar professor. Ao analisarmos o Programa Institucional de Iniciação à Docência (Pibid) que é desenvolvido pela Unisinos, entre outras Instituições de Ensino Superior, percebe-se a potência do Programa, mas também a sua limitação quando deixa de funcionar produzindo as 
tramas relacionais formativas, que precisam se desenvolverem para se constituírem um ethos de formação. O Pibid é uma possibilidade, mas não é garantia de uma formação qualificada; o ethos de formação seria a condição de possibilidade para a formação qualificada.

Outro conceito que considero importante para pensar de outros modos a formação de professores distante da lógica empresarial, considerando estudos do filósofo Michel Foucault, seria exercitar o pensamento por meio de uma crítica radical ou hipercrítica.

\begin{abstract}
A essa crítica radical, assim desconfiada até de si mesma, denominei hipercrítica (VEIGA-NETO, 1995).

Trata-se de uma crítica não metafísica, de modo que, não contando com pressupostos universais, ela dá as costas às metanarrativas iluministas e à crítica tradicional. Autorreflexiva, ou seja, suspeitando até de si mesma, a hipercrítica é difícil e incômoda, mas sempre aberta e provisória; consequentemente, é uma crítica humilde, pois não arroga a si o estatuto de melhor, verdadeira, definitiva e mais correta. (VEIGA-NETO, 2012, p. 274).
\end{abstract}

É essa crítica que nos possibilita historicizar, construir a história dos processos, analisar como os processos sociais se constituíram, descobrir suas tramas como invenções sociais, e não como procedentes de uma causa natural. Nesse processo, razão e sensibilidade podem dar as mãos para que se constitua um conceito de humanidade muito mais abrangente e inclusivo.

Outro conceito que considero produtivo para enfrentarmos o conceito de qualidade como performance em um sentido apenas mercadológico e concorrencial, é o de artesania, baseado na atividade dos artífices. Os estudos de Sennett contribuem para esse entendimento:

Os artífices orgulham-se sobretudo das habilidades que evo-
luem. Por isso é que a simples imitação não gera satisfação du-
radoura; a habilidade precisa amadurecer. A lentidão do tempo
artesanal é fonte de satisfação, a prática se consolida, permitin-
do que o artesão se aposse da habilidade. A lentidão do tempo
artesanal também permite o trabalho de reflexão e imaginação-
o que não é facultado pela busca de resultados rápidos. Maduro
quer dizer longo; o sujeito se apropria de maneira duradoura da
habilidade. (SENNETT, 2013, p. 328).

Essa qualidade que negocia o prazer de um trabalho bem feito com o sujeito que faz e o que recebe o trabalho parece ser produtiva para pensar a formação 
e o trabalho docente. Em outro artigo, Fabris (2015) já anunciava o quanto a avaliação poderia beneficiar-se desse conceito de artesania, pois funcionaria como uma estratégia para qualificação do trabalho docente e da própria formação. Além disso, na artesania, “[...] há a busca pela produtividade, mas pelo prazer de um trabalho realizado com comprometimento e compromisso (pessoal e social).” (FABRIS, 2015, p. 4).

Diante de tudo que foi exposto, reforço meu argumento de que ser herói não é uma condição da docência que preserva e desenvolve o coletivo, mas a jornada que o herói desenvolve pode inspirar-nos para nossos processos formativos de autoformação. Sempre saímos diferentes de uma experiência, tal qual como acontece na narrativa heroica. Talvez essa transformação produzida pela autoformação, própria da jornada do herói, em que ocorre a apropriação da experiência, possa ser útil para pensar os processos formativos, mas reitera-se que as performances dos heróis nos colocarão, quase sempre, frente a frustrações por não atingirmos níveis de excelência próprios para “não humanos”. Em uma entrevista que Sennett concedeu no lançamento de seu livro $O$ Artifice, ele aborda os efeitos perversos do capitalismo, mas anuncia sua crença no potencial de aprendizagem do ser humano (SENNET, 2009). Não nos esqueçamos disso. Temos que urgentemente reinventar novas formas de habitar nossas escolas e universidades, indo além do produtivismo e da pedagogia do herói, ou teremos que viver à mercê de uma escola transbordante (NÓVOA, 2012) e de uma “subjetividade superlativa”. (FERREEIRA, 2015).

\section{CONSIDERAÇÕES FINAIS}

Somos capazes de fazer outras coisas com nós mesmos e com os outros; depende de nossa atitude pensar de outras formas, pesquisar de outros modos e viver de maneira mais comprometida com o social. Reivindicamos o direito de sermos profissionais professores, mas é necessário termos a compreensão de que essa é uma profissão que nos basta em sua complexidade. Sem nenhum heroísmo, podemos ser profissionais que assumem a escola como espaço público de aprendizagens coletivas e individuais, com responsabilidade de ensinar os conhecimentos sistematizados e valorizados como patrimônio da humanidade, mas também com os novos e emergentes conhecimentos que essa sociedade contemporânea produz, entendendo essa ação como direito de todos. Ao assumirmos esse desafio diário, colocamos a pedagogia do herói, junto com as políticas públicas contemporâneas, sob suspeita 
constante, o que acaba nos posicionando também em uma situação desafiadora, mas extremamente necessária para nossa profissão. O desafio está posto: passar essas políticas sistematicamente pelo fio da navalha da crítica radical.

\section{REFERÊNCIAS}

AÇÃO EDUCATIVA. Banco Mundial em Foco: um ensaio sobre sua atuação na educação brasileira e na dos países que integram a Iniciativa Via Rápida na América Latina. São Paulo: Ação Educativa, 2005.

AFONSO, A. J. Nem tudo o que conta em educação é mensurável ou comparável. Crítica à accountability baseada em testes estandardizados e rankings escolares.

Revista Lusófona de Educação, n. 13, p. 13-29, 2009.

BALL. S. J. Profissionalismo, Gerencialismo e Performatividade. Cadernos de Pesquisa, v. 35, n. 126, p. 539-564, set./dez. 2005.

BERGOLD, A. Supervisão Escolar S/A: a produção de supervisoras gerentes em um programa de formação continuada. 2014. 146 p. Dissertação (Mestrado em Educação)-Universidade do Vale do Rio dos Sinos, São Leopoldo, 2014.

BRODBECK, C. F. Docência em ciências nas práticas pibidianas do subprojeto biologia e a fabricação de uma pedagogia da redenção. 2015. 166 p. Tese (Doutorado em Educação)-Universidade do Vale do Rio dos Sinos, São Leopoldo, 2015.

CAMPBELL, J. O herói de mil faces. São Paulo: Pensamento, 1995.

DAL'IGNA, M. C.; FABRIS, E. T. H. Constituição de um ethos de formação no Pibid/Unisinos: processos de subjetivação na iniciação à docência. Educação Unisinos, v. 19, p. 77-87, 2015.

FABRIS, E. T. H. A Pedagogia do Herói nos filmes Hollywoodianos. Currículo sem Fronteiras, v. 10, n. 1, p. 232-245, jan./jun. 2010.

FABRIS, E. T. H. A avaliação como estratégia de qualificação da formação docente: entre a qualidade da produtividade e a qualidade da artesania. In: COLÓQUIO DA AFIRSE, 22., Lisboa. Anais... Lisboa, 2015.

FABRIS, E. T. H. Representações de Espaço e Tempo no Olhar de Hollywood sobre a Escola. 2009. Dissertação (Mestrado em Educação)-Universidade Federal do Rio Grande do Sul, Porto Alegre, 1999. 
FERREIRA, M. S. Espetacularização da carreira docente: prêmio professores do Brasil como prática da economia da educação. 2015. Tese (Doutorado em Educação)-Universidade Federal do Rio Grande do Sul, Porto Alegre, 2015.

FISCHMAN, G. E. Dos professores super-heróis aos intelectuais comprometidos: limitações e possibilidades das narrativas redentoras em educação. Cultura e docência: novos olhares para a realidade educacional. In: REUNIÃO ANUAL DA ANPED, 32., 2009, Caxambu. Anais... Caxambu, 2009.

FOUCAULT, M. Segurança, território, população. São Paulo: Martins Fontes, 2008.

HERMANN, N. Ética \& educação. Outra sensibilidade. Belo Horizonte: Autêntica, 2014.

KORITIAKE, L. A. Atuação dos organismos internacionais na educação. In: VI Congresso Luso-brasileiro Anpae, 6., 2010, Sorocaba. Anais eletrônicos... Sorocaba, 2010. Disponível em: <http://www.anpae.org.br/iberolusobrasileiro2010/ cdrom/64.pdf>. Acesso em: 23 set. 2016.

MACHADO, R. Por uma genealogia do poder. In: FOUCAULT, M. Microfísica do Poder. Rio de Janeiro: Edições Graal, 1979.

NEVES, A. Qualidade na formação de professores: os cursos de pedagogia 5 estrelas. 2016. Dissertação (Mestrado em Educação)-Universidade do Vale do Rio dos Sinos, São Leopoldo, 2016.

NÓVOA, A. Entrevista com o Professor Antonio Nóvoa. Educação e Sociedade, Campinas, v. 33, n. 119, p. 633-645, abr./jun. 2012.

OECHSLER, K. M.; SILVA, N. M. A. O bom professor na Revista Nova Escola: do herói ao profissional ativo. Atos de Pesquisa em Educação, v. 7, n. 4, p. 12021223, dez. 2012.

OLIVEIRA, S. Tornar-se professor/a: matriz de experiência e processos de subjetivação na iniciação à docência. 2015. Tese (Doutorado em Educação)-Universidade do Vale do Rio dos Sinos, São Leopoldo, 2015.

SANTOS, A. S.; FERREIRA, L. M. A. Jornada do Herói no Cinema: considerações mitodológicas acerca da saga Star Wars. Correlatio, v. 14, n. 28, dez. 2015.

SCHERER, R. P. Cada um aprende de um jeito: das adaptações às flexibilizações curriculares. 2015. Dissertação (Mestrado em Educação)-Universidade do Vale do Rio dos Sinos, São Leopoldo, 2015. 
SCHNEIDER, M. P.; NARDI, E. L. Accountability em educação: mais regulação da qualidade ou apenas um estágio do Estado-avaliador? ETD - Educação Temática Digital, Campinas, v. 17, n. 1, p. 58-74, abr. 2015. Disponível em: <http://periodicos.sbu.unicamp.br/ojs/index.php/etd/article/view/8634818>. Acesso em: 09 out. 2016.

SENNETT, R. Entrevista Revista IHU. São Leopoldo, 2009.

SENNETT, R. O artífice. 2. ed. Rio de Janeiro: Record, 2013.

SILVA, R. R. D.; FABRIS, E. T. H. Políticas de Currículo para o Ensino Médio no Brasil Contemporâneo: o que ensina aos jovens a escola que protege? Revista Educação e Sociedade, Campinas, v. 37, n. 135, p. 352-363, maio/jun. 2016.

VEIGA-NETO, A. É preciso ir aos porões. Revista Brasileira de Educação, v. 17, n. 50, maio/ago. 2012.

VEIGA-NETO, A. Educação e governamentalidade neoliberal: novos dispositivos, novas subjetividades. In: PORTOCARRERO, V.; CASTELO BRANCO, G. Retratos de Foucault. Rio de Janeiro: Nau, 2000.

VEIGA-NETO, A. Educação e Pós-Modernidade: impasses e perspectivas. Rio de Janeiro: PontifíciaUniversidade Católica do Rio de Janeiro, 2005.

VEIGA-NETO, A. Michel Foucault e Educação: há algo de novo sob o sol? In: VEIGA-NETO, A. (Org.). Crítica Pós-Estruturalista e Educação. Porto Alegre: Sulina, 1995.

VICENTINI, P. P.; ALVES, A. Professor: herói, coitado ou vilão para a Revista Veja? Uma análise das imagens veiculadas sobre o magistério no periódico da Editora Abril (1996-2008). In: ENCONTRO NACIONAL DE DIDÁTICA E PRÁTICAS DE ENSINO, 16., 2012, Campinas. Anais... Campinas, 2012.

ZEICHNER, K. M. Políticas de Formação de Professores nos Estados Unidos. Como e por que elas afetam vários países do mundo. Belo Horizonte: Autêntica, 2013.

Recebido em: 08 de março de 2017 Aceito em: 18 de julho de 2017

Endereço para correspondência: Av. Unisinos, 950, Cristo Rei, 93020-190, São Leopoldo, Rio Grande do Sul, Brasil; ethfabris@gmail.com 
